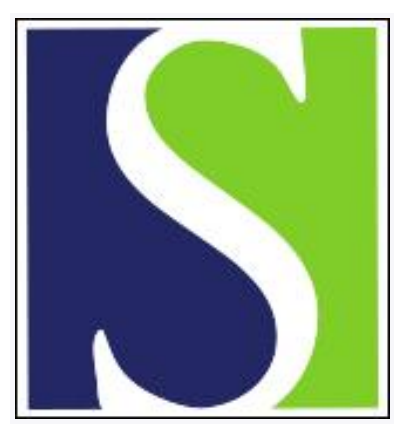

Scand J Work Environ Health 1984;10(6):419-428

https://doi.org/10.5271/sjweh.2318

Issue date: Dec 1984

Causes, prediction and prevention of back pain at work. by Troup JD

This article in PubMed: www.ncbi.nlm.nih.gov/pubmed/6242075

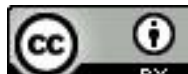




\title{
Causes, prediction and prevention of back pain at work
}

\author{
by JDG Troup, PhD, MRCS, LRCP 1
}

\begin{abstract}
TROUP JDG. Causes, prediction and prevention of back pain at work. Scand $J$ Work Environ Health 10 (1984) 419-428. Pain in the back and lower limbs due to lumbar disorders has a multifactorial etiology, and there is no clear relationship between the morbid pathological change observed and the symptoms experienced. Of the precipitating factors, unaccustomed heavy work, postural fatigue, and injury are common. "Back injury," however, embodies a variety of phenomena, few of which can readily be distinguished either in national statistical data or in previous epidemiologic studies. Thus the causal relationship between back pain and work is far from clear, a difficulty compounded by the prevalence of back symptoms in all groups of the population. There are few epidemiologically established methods for identifying people who are susceptible to a first attack of back pain, though, once back pain has been reported, recurrence may be predicted. Selection of the preventive approach depends on reliable information about the prevalence of back pain/discomfort, the back injury rate, sickness absence, etc; about accidents, work stoppages, job turnover, or any other pointers to the design of the workplace or work practices; and about the resulting losses of productivity and the costs of the remedy. Though the decisions are up to management, the quality of the information required is mainly an occupational health responsibility.
\end{abstract}

Key terms: accident investigation, epidemiology, industrial injury, lifting loads, preemployment selection, prognostic factors, recurrence rates, training.

Pain caused in the back, hips, and lower limbs by mechanical derangement of the lumbar spine presents one of the commonest and most costly problems in occupational health. The reported incidence of back injury and accidents related to manual materials handling is high $(3,93)$, and the overall costs are greater for injury to the back than for any other category $(101,102)$. The association between back pain and heavy manual work has long been recognized, particularly since the Swedish (42) and British (47, 55) reports of early degenerative change in the lumbar spine associated with heavy work.

This association has tended to dominate the approach to prevention. Bioengineering research was concentrated on the failure strength of lumbar vertebral bodies and discs. The biomechanical approach has focused on determining the peak values for the compressive loading of the lumbosacral disc. Such evidence has led, for example, to the proposals, published by the National Institute for Occupational Safety and Health (67), that manual work inducing compressive loads not exceeding $350 \mathrm{~kg}$ requires no intervention, that action is indicated for higher loading, and that $650 \mathrm{~kg}$ should be the maximum

\footnotetext{
1 Department of Orthopaedic and Accident Surgery. The University of Liverpool, Liverpool, England, and The Institute of Occupational Health, Helsinki, Finland.
}

Reprint requests to: Dr JDG Troup, University Department of Orthopaedic and Accident Surgery, Royal Liverpool Hospital, PO Box 147, Liverpool L69 3BX, England [UK]. load permissible. Psychophysical data on acceptable levels for dynamic manual work (81) and data based on measurements of intra-abdominal pressure during static exertions of force (27), both with supporting epidemiologic evidence $(26,69,82)$, are alternative criteria which are applicable to prevention.

The drawback to these approaches to the prevention of back pain is that, being based on data from normal material or normal populations, they are applicable only to comparable population groups and not to any individual. One solution is to limit the weight handled according to the maximal isometric strength of the individual. Chaffin et al (17) have proposed strength testing in relation to the forces required for manual materials handling at work in order to avoid a mismatch between job and worker and to ensure an adequate margin of reserve strength. With this approach, as with the preceding three, the presumption is that back injuries may be prevented simply by reducing the magnitude of the weights handled. With each approach the applicability is exclusively to bimanual, symmetric exertions of force.

Such preventive measures have been locally successful. In general the 50-kg sack is being replaced by the $25 \mathrm{-kg}$ sack. Mechanical handling equipment is used increasingly to replace manual lifting and carrying. Yet back pain remains a major problem, and reported injury rates have tended to remain constant (93). If prevention is to be successful, a more realistic appraisal of the etiology of back injuries and back symptoms at work is essential. 


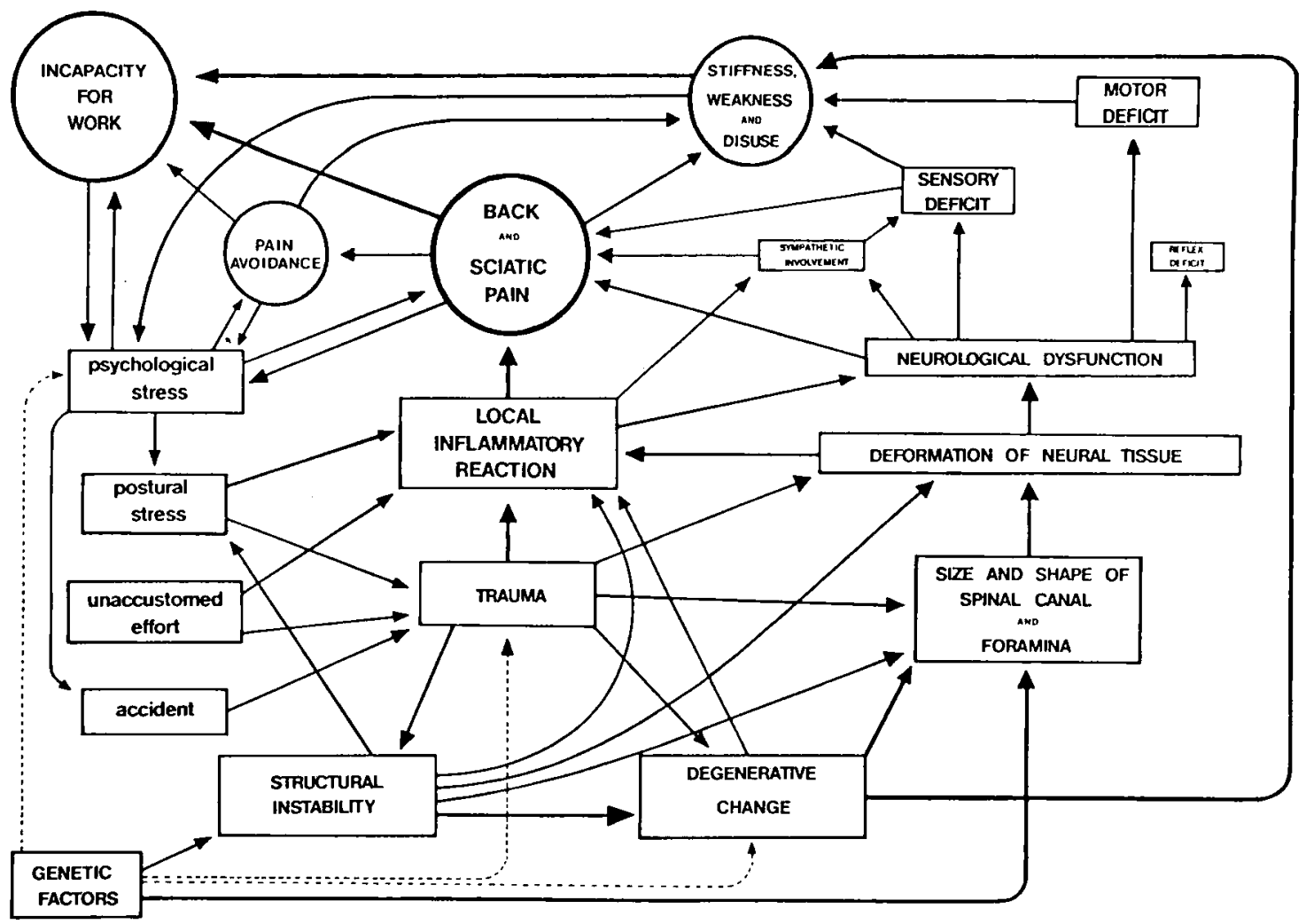

Figure 1. The multifactorial etiology of back pain [reprinted from Lloyd \& Troup (59)].

It must also be appreciated that few, if any, of the epidemiologic studies of low-back pain have been based on reliable diagnostic data, for a truly accurate diagnosis is only attempted if surgery is contemplated - and even then the diagnosis often proves to be imprecise. In this paper, therefore, no diagnostic distinctions will be made, and consideration will only be given to the total spectrum of mechanical derangements of the lumbar spine with related pain in the back, hips, and legs.

\section{Causes of back pain}

\section{Multifactorial etiology}

Back pain has a multifactorial etiology. Not only are there many factors which may contribute, but the factors tend to interact (figure 1). For instance an unskilled manual worker may have a minor congenital anomaly in the spine, have a relatively narrow spinal canal or intervertebral foramen, and have been exposed over a number of years to repeated subclinical injuries producing microtraumata without significant symptoms; but an acute attack of back pain is triggered by a change in work procedure and unaccustomed activity. A subsequent attack a few months later may be potentiated by a residue of stiffness and weakness from the initial attack and by psychosocial factors, but it may be triggered by postural stress. Both episodes might be reported as back injuries. Both might be categorized in official statistics as due to materials handling. But the question remains of the cause of the back pain in such a case. A full occupational and medical history and information on work capacity, the physical demands of the work and the work environment, together with data on the precipitating factors, are all essential to the etiology in any one case, as well as to prevention for all those at risk.

In addition account must be taken of the physical work load incurred during leisure activities and at home - looking after young children, for example, which, in a study of nurses, appeared to be an additional and confounding factor (97).

\section{Aggravating and precipitating factors}

Back injuries are reported more commonly for heavy than for light work $(3,84)$, the younger, unskilled, and inexperienced worker being at greater risk $(2,13$, $25,26,84,97)$. Official data also show that "handling" is the commonest reported cause of back injury. However, a recent review of statistics from the Health \& Safety Executive in Great Britain shows that, although the back is injured in $61 \%$ of injuries classified as "overexertion, etc," and that $74 \%$ of these back injuries are attributable to "lifting, etc," 
there is very far from being a one-to-one relationship between back injuries and handling in industry (93). In fact less than half of all the injuries ascribed to "overexertion, etc" involved back injuries due to lifting. Yet, in occupations with specific risks, the incidence of back injuries due to lifting may be relatively high, as in nursing, for which the annual incidence of all cases of back pain, the onset of which is attributed to patient handling, has been reported to be 159 per 1000 at risk per year (83).

Stooping, sitting, and heavy lifting have been identified by numerous authors as factors that contribute to the onset of back pain $(8,9,10,31,32,61,62,97$, 98 , as has also unexpectedly heavy loads and infrequent lifting (61). Whole-body vibration, as when heavy vehicles are being driven, has been suggested as a factor to account for the prevalence of back pain among drivers $(48,91)$. Chaffin \& Park (18) drew attention to a mismatch between individual strength and the exertions of force required at work as another contributory factor.

Although, in many of the studies already mentioned, there was a presumption that the back was injured, the actual evidence for injury in the sense of acute trauma is seldom explicit. Mostly they concern acute back pain attributed to work and reported as injuries. In all such data the cause of injury is ascribed to a single factor. No distinction is made between a truly accidental injury in which the normal pattern of activity is disrupted unexpectedly (so that tissues may be damaged as a direct result, as in the case of a fall or a blow on the back) and a nonaccidental injury. In the latter there is no disruption of the normal pattern of work, and the only unexpected event is pain in the back, a distinction which may be diagnostically and prognostically significant $(59,95)$. Before such a distinction can be made, a detailed history is needed to reveal the sequence of events leading to the injury.

The sequence of events is essential to the "Swedish Information System on Occupational Injuries" developed at the National Board of Occupational Safety and Health in Sweden. Lagerlöf et al (53) analyzed 15000 work-related back injuries and found that lifting or strenuous movement was a factor in $85 \%$ of the cases studied, and it was the immediate cause in $60 \%$. Shannon \& Manning (80) developed an accident model based on the identification of the first unforeseen event and the associated activities and movements in the sequence of events leading to injury. Manning et al (63) used this model to analyze the causes of 122 truly accidental back injuries and found that "underfoot accidents" (ie, in which the first unforeseen event was, for example, the slipping of a foot) formed $66 \%$ of the total. "Handling"' was a primary or secondary activity in only $32 \%$ of the truly accidental back injuries, but it was a factor in $63 \%$ of the nonaccidental back injuries in which back pain was the first unforeseen event.

\section{Biomechanical factors}

Studies of osteoligamentous specimens of the lumbar spine have shown that the mechanical response to loading varies with time. Perey (73) found that the capacity of the vertebral bodies and discs to resist compressive loading was inversely related to the duration of the applied static load. Whenever the compressive load exceeds the interstitial osmotic pressure, fluid is expelled and the disc narrows so that the intervertebral joint-complex stiffens and its dynamic response characteristics are changed $(46,52)-$ the result of creep effects. Thus the longer the spine is subjected to compressive loading, the greater the likelihood of failure or susceptibility to trauma. The creep phenomenon has been described as a response to both static and dynamic loading, including the vibratory form $(22,45)$, and it occurs more rapidly in the presence of disc degeneration (46).

Cyclic loading of the spine may also lead to fatigue failure of bone, either in the neural $\operatorname{arch}(21,90)$ or in the trabeculae of vertebral bodies (58).

Creep effects in response to static and dynamic loading must be considered in relation to diurnal changes in the height of the disc, and thus of the vertebral column, and the overall effects on stature. In vivo, the change in disc height cannot be precisely measured, but it is now possible to determine body stature with an accuracy of $1 \mathrm{~mm}$ (30). The total diurnal shrinkage in stature is of the order of $1 \%$ (76) though it decreases with age (51). In one study the shrinkage of young healthy males over 20-min periods was proportional to the applied load, dynamic lifting exercise led to significantly greater shrinkage than static loading with the same weight, and over periods of $10 \mathrm{~min}$ different resting postures led to significantly different rates of recovery in stature (96). Eklund \& Corlett (30) also found marked differences in shrinkage over periods of $1 \mathrm{~h}$. The differences were dependent on the design of the chair or seat used, and, overall, the rates of shrinkage were proportional to the calculated lumbar compression.

At present there is little or no epidemiologic evidence for the biomechanical factors which may contribute to back pain, except for those of a subjective or circumstantial kind. Lumbar spinal function nevertheless varies markedly during the course of the day. This variation is partly a result of diurnal changes in the height of the vertebral column. But the resulting shrinkage in stature can also be produced by relatively short periods of static or dynamic work - though the longer the work continues, the greater the effect and the longer the period needed for recovery. When the height of the vertebral column is thus reduced, the tissues stiffen, energy is dissipated less efficiently under vibratory or jerk forces, and the tissues are more readily injured. This is the basis for the interaction between the postural stress and trauma illustrated in figure 1 . 


\section{Prediction of back pain}

\section{Individual factors}

The one epidemiologically established factor for predicting back pain is evidence of a previously reported episode such as previous consultation for treatment $(28,41)$, previous sickness absence $(8,9,10,40,44$, $85,95)$ and its duration $(4,8,9,10,95)$, and the number of previous episodes and residual symptoms, particularly in the leg, after the acute phase of the attack has subsided $(4,59,95)$. But because of the prevalence of back symptoms in the population, the criterion for what is etiologically significant as previous back pain may have to be clarified. Given the tendency of patients with recurrent back pain to have a higher consultation rate for other disorders $(87 \&$ unpublished data of RW Porter), the criterion may have to be based either on a number of factors concerning previous back trouble or on a measure such as "the intensity of work recovery" (4). Nevertheless the feasibility of using previous back trouble as a predictive factor is limited by the ease with which the facts can be concealed.

Nordgren et al (70) carried out a detailed clinical examination of army reservists prior to field service and found that palpatory tests, based on an osteopathic technique, were of value in predicting back pain. Biering-Sørensen (11) reported that, for males from a cross-sectional study of the population, the Schober test of lumbar flexibility and an endurance test of back muscle strength had some value for predicting a first attack. But in an industrial environment the reported pain or discomfort which determines whether such tests are deemed to be positive or negative may also be concealed.

Karvonen et al (44) found physical fitness, as evidenced by poor running performance, to be of predictive value for military conscripts. Cady et al (16) used a battery of tests, including lumbar mobility, strength, and exercise response in a study of firefighters; they found that the group labeled "most fit" had significantly fewer subsequent back injuries than the other groups, although the few injuries they did sustain were more severe. Physical fitness appears to confer a greater tolerance for pain $(15,79)$, but it is conceivable that physically fit subjects are more exposed to injury on account of greater strength and greater speed of motion.

Chaffin and his colleagues at the University of Michigan have developed a technique for testing the isometric lifting strength of workers and relating individual results to the strength requirements of work. The relatively weaker workers, with a smaller margin of strength in reserve, reported more episodes of back pain $(17,18)$. Keyserling et al $(49,50)$ have shown such tests to have predictive value for "medical episodes" of musculoskeletal symptoms, including back pain. However, it should be noted that the tests, as described, are mainly relevant to symmetrical handling tasks which are repetitive. Other work conditions may require that such tests be modified.

Other predictive factors which have been adduced concern the size and shape of the body. These include tallness $(39,64,88)$, the "long back" (64), and obesity (44). Such factors may be significant where there are spatial restraints which cramp the movements or posture of persons with larger dimensions. Asymmetry of leg length with secondary pelvic tilt is also claimed to be commoner in those with back pain $(6,37)$ but, as with other anthropometric tests, there are insufficient data on which to base a prediction.

\section{Radiographic data}

The Ad Hoc Committee on Low Back X-rays (1) published a set of criteria for lumbar spinal radiographs and arbitrarily defined a number of radiographically observed abnormalities, such as spondylolisthesis, as risk factors. None of the epidemiologic studies since then have confirmed these abnormalities as risk factors to a measurable extent, though Horal (40) found spondylolysis and spondylolisthesis to be more common in those with back pain. Redfield (75) categorized the radiographs of 2378 timber workers according to the $A d$ Hoc Committee's criteria and found the injury rate higher in the "low risk" group. Gibson et al (36) reported no benefits from using such radiographic data as a screening process. Bigos et al (12) analyzed radiographic data from three groups: 208 normal subjects, 223 people after their first reported back injuries, and 162 persons with chronic back pain. There were no significant radiographic differences between the three groups. It should be added however that few of the studies were big enough to yield comparative data on all radiographic abnornalities. Spondylolisthesis, for example, is present in between 2 and $10 \%$ of the population, depending on race, sampling, etc, but no attempt has been made in epidemiologic studies to distinguish between the causes of spondylolisthesis and the segmental level in the vertebral column at which the condition is seen, in spite of the differences in the natural history of the different causes (68). Even when an anomaly such as sacralization (transitional presacral vertebra) was fully reviewed and categorized in a series of 7236 cases of the disturbance (89), the risk factors remained low.

\section{Occupational factors}

The heaviness of lifting has been well recognized as a factor likely to cause back pain $(20,23,26,60,77$, $85)$, as has postural stress at work $(54,78)$. Other occupational factors have attracted little epidemiologic attention although, based on biomechanical and psychophysical evidence, they may be potentially significant.

The mass of the object handled is implicit in the perception of heaviness. Dimensions are also signifi- 
cant as the bulkier the object the greater the distance of its center of mass from the body, a phenomenon which affects the stresses induced in the spine, as well as the acceptable weight of the object to be lifted (33, 34). People can carry less weight in a container when the contents, if fluid, for example, are free to move within it (66). The lack of handles on a container also reduces its liftable weight (35).

If an object can be held against the body, the vertical load on the upper limbs and spine is reduced (19). Similarly the stresses induced in the spine and the trunk are less if a weight can be lifted from the floor in two phases, the lifter first bringing the weight onto the thighs before coming to the erect position (94).

The height at which objects are lifted is significant to the posture adopted by the body. Some lifting techniques, for example, lifting from the floor in a stooped position with the knees straight, induce a high static component of Iumbosacral compression (56). The static load may be prolonged if accuracy of placement is at a premium or if there are spatial restraints on posture and movement (29).

Other occupational factors that may be potentially relevant to back symptoms include the rhythm and frequency of lifting (43) and, in particular, the provision of lifting aids and mechanical handling equipment.

\section{Prediction of the recurrence of back pain}

Interview and examination on return to work is more likely to have prognostic value than if they take place when the pain is still in the acute phase. The presence of residual pain, particularly in the leg, the duration of sickness absence for the current attack, and the number of previous episodes have all been identified as significant predictive factors $(4,8,9,59,72,95)$. In one study (59) the clinical signs of significant predictive value for men seen on return to work were as follows:

(i) restriction of the pain-free range of straight-legraising, either unilaterally by $15^{\circ}$ or absolutely to $45^{\circ}$ or less;

(ii) positive qualifying tests for root tension in association with the straight-leg-raising test $(14,92)$;

(iii) inability to "sit-up";

(iv) pain or weakness on resisted hip flexion;

(v) back pain on passive lumbar extension with the patient prone.

Pedersen (72) found straight leg raising to be of predictive value in a study from general practice. In a cross-sectional study Biering-Sørensen (11) reported that the limitation of the hamstring stretch, the finger-tip-to-floor distance on stooping, the capacity to "sit-up," and lumbar mobility all showed some value as predictors. The trends were evident for both sexes.

\section{Approaches to prevention}

There are four approaches to preventing back pain at work: ergonomics, safety training, preemployment selection, and treatment-rehabilitation. To some extent they overlap.

\section{Ergonomics}

Ergonomics is the foremost approach to prevention. If the workplace, the equipment, and the work procedures are ergonomically satisfactory, the task should, by definition, be safe and comfortable. It is therefore axiomatic that the physical demands made on the workers should be within their work capacity. Ergonomics requires a broad approach with knowledge of engineering, production management, and the human biological disciplines. It belongs properly at the beginning of the process of design although it is often expedient to settle for piecemeal improvements in an existing workplace. The indications that ergonomic intervention is called for include high levels or upturns in sickness absence, the injury rate, and the frequency of near-accidents, work stoppages, and the rate of job turnover.

\section{Safety training}

Requirements for safety training are embodied, in many countries, in the laws and regulations concerning health and safety at work. There is however little guidance on how such training should be conducted, and this lack, perhaps, reflects the want of epidemiologic evidence of the value of training. Snook (81) found no such evidence.

In the past there has been widespread reliance on teaching people how to lift by rote, enjoining them to adopt "correct hand hold," "correct foot position," and to lift "with the legs," "with a straight back," "with arms close to the body," "with the chin tucked in," and "with correct use of body weight." Yet lifting from the floor with a straight back by extending the hips and knees offers few significant advantages in terms of the stress on the spine and trunk (57, 94). Such drills contain no principle of safe lifting, and the concept of a universally applicable, "correct"' method is biologically nonsense.

There are, though, a number of reports indicating falls in the incidence of back injuries after the introduction of training programs designed for specific occupational lifting problems $(5,65,74,103,104)$. None of these studies was properly controlled however. Their successes may partly be attributable to the training itself, but in some cases the propaganda or other interventions such as ergonomics may have been instrumental. Nevertheless, when the legal obligations to provide safety training are considered, there are a number of theoretical principles to include 
in any program of training for safety in lifting and handling (93); they are:

1. The dangers of careless and unskilled handling methods.

2. The principles of levers and the laws of motion.

3. Functional anatomy of the vertebral column and musculoskeletal system.

4. Effects of lifting, pushing, pulling, and carrying on the body, with emphasis on potentially harmful postures or movements.

5. The following components of skill:

(i) preparation to avoid the unexpected;

(ii) knowledge of how much can be handled comfortably without help;

(iii) advantage of keeping the load close to the body;

(iv) avoidance of twisting and bending sideways during exertion;

(v) use of the legs to get close to the Ioad, to provide stability, and to help make use of body weight and the kinetic energy of the body and load.

\section{The use of mechanical aids to handling.}

The actual content of such training depends on the responsibilities and educational background of the trainees.

The aim of training in lifting and handling is generally to increase skill. But it should lead to handling which feels easier and needs less effort. Although the introductory part of the training may be conveniently conducted in the training school or classroom, all practical aspects of the training should be taught at the workplace. The training program should begin with management and supervisory staff. If only newcomers to the workplace are trained, or only junior employees, there is a danger that they will be inhibited from putting the safer handling methods into practice by the ingrained habits of older workers. Last, it is essential that the teaching capacity of the trainers themselves and the results of training should be monitored and evaluated.

\section{Preemployment selection}

The problem with selection is the want of epidemiologic evidence for the predictive value of preemployment testing. Though a number of tests have been shown to have predictive value, they were evaluated in nonindustrial settings $(11,44,70)$. Medical histories of previous back pain may not be available. It is not difficult to conceal the pain or discomfort of a clinical examination when there is an incentive. In fact, in the course of a preemployment medical examination, it may only be possible to exclude the more readily diagnosable conditions which affect manual work capacity and state that the individual appears to be fit for manual work, subject to a successful outcome of training and physiological adaptation. A more rigorous approach may only be feasible when the safety of others is at risk (for example on recruitment for the rescue services) or for jobs with a high risk of spinal injury.

Some consideration should be given however to strength testing. Isometric strength testing in relation to the force requirements of the job, as defined by Chaffin and his colleagues in the studies already quoted, appears to have a place, certainly for repetitive, bimanual, symmetric manual handling work. One alternative may be to use isometric endurance testing, shown by Biering-Sørensen (11) to have prognostic value in a general population study. Another alternative may be to adopt psychophysical ratings of acceptable handling strength. Griffin et al (38) studied 350 people, of whom $19 \%$ reported that they experienced some back pain at least once a month. The isometric lifting strength did not differ significantly between the "back pain group" and the others, but the ratings of acceptable lifting strength were significantly less for both males and females. Prospective epidemiologic data on psychophysical ratings of acceptable lifting strength or ratings of perceived exertion are not yet available.

The radiographic screening of workers engaged in heavy manual work was at one time strongly advocated in the United States, but the lack of supportive epidemiologic evidence (12), together with the known hazards of radiation, have almost ruled it out. In theory it may be deemed advisable for employment in work with exceptional risks of injury, but the criteria have never been defined. Radiographic screening for practical purposes is limited to use with persons who have a disability and who need medical advice on job placement, though seldom do radiographs have to be taken specifically for this purpose, provided recent pictures are available.

\section{Treatment and rehabilitation}

It has been claimed that early treatment has a preventive role for back pain $(99,100)$, but there have been no controlled therapeutic trials which have yet confirmed it (7). Much depends on local conditions. Where treatment can be offered at work more rapidly than through the normal channels of a national health service, it is probable that the duration of incapacity will be shorter. However, this hypothesis appears not to have been tested. But this is only one aspect of the potentially preventive role of treatment and rehabilitation. Primary medical care at work provides an opportunity to investigate the causes of back injury and the occupationally related causes of persistent backache, information which can be of use when other preventive approaches are applied. Can the workplace, for example, be modified to take account of individual disability or can the work procedure be 
restructured? Does the individual require to be retrained or his physical fitness improved? Or should the individual be counseled to change jobs?

\section{Planning the preventive program}

Any action aimed at the prevention of back injuries or backache at work incurs a cost which has to be weighed against the overall costs of both the injuries themselves and the losses in productivity which arise in the presence of back symptoms (24). The costs of an injury attributed to work include the results of the disruption of work at the time of injury and the costs of labor replacement pending a return to work of the casualty, quite apart from the medical and health insurance costs.

An ergonomic solution can be expensive depending on the amount of rebuilding or reequipping that is necessary. Safety training is expensive in terms of the time spent by both trainers and trainees on nonproductive activity. Preemployment, or reemployment, medical screening and the provision of primary medical care at work add to the cost of the occupational health service. Unfortunately there are few published data on the cost benefits that accrue. Blow (unpublished data) found that safety training for manual handling was cost effective in an electrical factory, and, more recently, Saari (personal communication) has reported cost benefits following the introduction of a new system of accident investigation. It may therefore be postulated, if not strongly urged, that the time and effort devoted to the prevention of back trouble at work will be more than justified on financial grounds.

The success of a preventive program depends on the quality of information on which its choice is based. Knowledge of the physical work capacity of each employee and of the demands of the job, in terms of the postural constraints and handling forces required, is essential. Work capacity can be assessed in terms of productivity, and psychophysical ratings can be made of the perceived effort or exertion. With some types of work it may be necessary to compare the individuals' maximal strength or energy expenditure with the actual forces and exertion required. So far as lumbosacral stress is concerned, it is only possible, except in a laboratory, to make a "rule-ofthumb" estimate based on a simple static model (67) with the attendant disadvantage that the dynamic component of lumbosacral compression and any effects of rotation are not accounted for (93). Unfortunately none of the current methods of work analysis (eg, AET, OWAS, RENAULT, AVISEM) give reliable enough data for this purpose. New methods of evaluating back stress at work, taking into account the temporal pattern of all handling and postural stresses, are needed, and some are being developed $(30,71,96)$. These new methods will go part of the way towards identifying the right preventive approach, but more data on other risk factors are needed.

Before the right choice for the prevention of back trouble and handling problems can be made, a comprehensive informational system is needed that may be summarized as follows:

Medical data: truly accidental back injuries, nonaccidental back injuries, other injuries associated with lifting/handling, therapeutic needs for workers with back pain, prevalence of work-related back symptoms.

Accident-investigation data: accidents culminating in injury, near accidents.

Work analysis: magnitude and frequency of handling stress, duration of postural stress.

Individual work capacity: maximal strength, endurance strength, physical fitness, mobility.

Production data: work stoppages, job turnover, maintenance problems.

In larger organizations with well-staffed occupational health centers, the generation of reliable data should present no problem. It is up to the health personnel to persuade management of the strength of their case, using, where necessary, the appropriate commercial argument. In smaller firms, with no occupational health service on site, the problem is one of the education of management, and this process could be one of the functions of the national organizations for health and safety at work. It is not enough only to educate safety officers and industrial training instructors. The responsibility lies with the management, and they, too, need to be educated.

\section{References}

1. Ad Hoc Committee on Low Back X-Rays. Low back $\mathrm{X}$-rays: Criteria for their use in placement examinations in industry. J Occup Med 6 (1964) 373-380.

2. Afacan AS. Sickness absence due to back lesions in coal miners. J Soc Occup Med 32 (1982) 26-31.

3. Andersson GBJ. Epidemiologic aspects on low-back pain in industry. Spine 6 (1981) 53-60.

4. Andersson GBJ, Svensson H-O, Odén A. The intensity of work recovery in low back pain. Spine 8 (1983) $880-884$.

5. Andrews SJM. Deadline: 24 hours to train 500 persons. Johnson Matthey Bull 26 (1971) 13.

6. Beal MC. A review of the short leg problem. J Am Osteopath Assoc 50 (1950) 109-121.

7. Bergquist-Ullman M, Larsson U. Acute low back pain in industry: A controlled prospective study with special reference to therapy and confounding factors. Acta Orthop Scand Suppl 170 (1977). 1-117.

8. Biering-Sørensen F. A prospective study of low back pain in a general population: I Occurrence, recurrence and aetiology. Scand J Rehabil Med 15 (1983) 
$71-79$.

9. Biering-Sørensen F. A prospective study of low back pain in a general population: II Location, character aggravating and relieving factors. Scand $\mathrm{J}$ Rehabil Med 15 (1983) 81-88.

10. Biering-Sørensen F. A prospective study of low back pain in a general population: III Medical service work consequence. Scand J Rehabil Med 15 (1983) 89-96.

11. Biering-Sørensen F. Physical measurements as risk indicators for low back trouble during a one year period. Spine 9 (1984) 106-109.

12. Bigos $\mathrm{S}$, Hansson $\mathrm{T}$, Wortly MD, Beecher P. X-ray predictive value for low back injuries and high cost claims evaluated. Paper read at the 1983 annual meeting of the International Society for the Study of the Lumbar Spine in Cambridge, England.

13. Blow RJ, Jackson JM. An analysis of back injuries in registered dockworkers. Proc R Soc Med 64 (1971) $753-757$.

14. Breig A, Troup JDG. Biomechanical considerations in the straight-leg-raising test: Cadaveric and clinical studies of the effects of medial hip rotation. Spine 4 (1979) 242-250.

15. Brooke JD. Extraversion, physical performance and pain perception in physical education students. Res Phys Educ 1 (1967): 2, 25-30.

16. Cady LD, Bischoff DP, O'Connell MS, Thomas PC, Allan JH. Strength and fitness and subsequent back injuries in firefighters. J Occup Med 21 (1979) 269-272.

17. Chaffin DB, Herrin GD, Keyserling WM. Preemployment strength testing - An updated position. J Occup Med 20 (1978) 403-408.

18. Chaffin DB, Park KY. A longitudinal study of lowback pain as associated with occupational weight lifting factors. Am Ind Hyg Assoc J 34 (1974) $513-525$.

19. Coury BG, Drury CG. Optimum handle position in a box-holding task. Ergonomics 25 (1982) 645-662.

20. Cust G, Pearson JCG, Mair A. The prevalence of low back pain in nurses. Int Nurs Rev 19 (1972) 169-179.

21. Cyron BM, Hutton WC. The fatigue strength of the lumbar neural arch in spondylolysis. J Bone Jt Surg 60-B (1978) 234-238.

22. Cyron BM, Hutton WC. The behaviour of the lumbar intervertebral disc under repetitive forces. Int Orthop 5 (1981) 203-207.

23. Damlund M, Gøth S, Hasle P, Munk K. Low-back pain and early retirement among Danish semiskilled construction workers. Scand J Work Environ Health 8 (1982): suppl 1, 100-104.

24. Daniel JW, Fairbank JCT, Vale PT, O'Brien JP. Low back pain in the steel industry: A clinical, economic and occupational analysis at a North Wales integrated steelworks of the British Steel Corporation. J Soc Occup Med 30 (1980) 49-56.

25. Darre E, Ammundsen A, Fabrin J, Hansen LB, Thorsteinsson B. Rygbesver blandt nyindkaldte danske vaernepligtige. Ugeskr Laeg 144 (1982) 788-791.

26. Davis PR, Sheppard NJ. Pattern of accident distribution in the telecommunications industry. $\mathrm{Br} \mathrm{J}$ Ind Med 37 (1980) 175-179.

27. Davis PR, Stubbs DA. Force limits in manual work. IPC Science and Technology Press, Guildford, England 1980.

28. Dillane JB, Fry J, Kalton G. Acute back syndrome A study from general practice. Br Med J 2 (1966) $82-84$.

29. Drury CG. The influence of restricted spaces on manual materials handling. In: Davis PR, Troup JDG, ed. Proceedings of the Seminar on the Prevention of Low Back Pain, Luxembourg 1983. Taylor \& Francis Ltd, London (in press).
30. Eklund J, Corlett EN. Shrinkage as a measure of the effect of load on the spine. Spine 9 (1984) 189-194

31. Frymoyer JW, Pope MH, Clements JH, Wilder DG, MacPherson B, Ashikaga T. Risk factors in low-back pain: An epidemiological study. J Bone Jt Surg 65-A (1983) 213-218.

32. Frymoyer JW, Pope MH, Costanza MC, Rosen JC, Goggin JE, Wilder DG. Epidemiologic studies of low-back pain. Spine 5 (1980) 419-423.

33. Garg A, Mital A, Asfour SS. A comparison of isometric strength and dynamic lifting capability. Ergonomics 23 (1980) 13-27.

34. Garg A, Saxena U. Effects of lifting frequency and techniques on physical fatigue with special reference to psychophysical methodology and metabolic rate. Am Ind Hyg Assoc J 40 (1979) 894-903.

35. Garg A, Saxena U. Container characteristics and maximum acceptable weight of lift. Hum Factors 22 (1980) 487-495.

36. Gibson ES, Martin RH, Terry CW. Incidence of low back pain and pre-placement $\mathrm{x}$-ray screening. $\mathrm{J}$ Occup Med 22 (1980) 515-519.

37. Giles LGF, Taylor JR. Low-back pain associated with leg length inequality. Spine 6 (1981) 510-521.

38. Griffin AB, Troup JDG, Lloyd DCEF. Tests of lifting and handling capacity: Their repeatability and relationship to back symptoms. Ergonomics 27 (1984) $305-320$.

39. Gyntelberg F. One year incidence of low back pain among male residents of Copenhagen aged $40-59$. Dan Med Bull 21 (1974) 30-36.

40. Horal J. The clinical appearance of low back disorders in the city of Gothenburg, Sweden. Acta Orthop Scand Suppl 118 (1969) 1-109.

41. Hull FM. Diagnosis and prognosis of low back pain in three countries. J R Coll Gen Pract 32 (1982) $352-356$.

42. Hult L. Cervical, dorsal and lumbar spinal syndromes. Acta Orthop Scand Suppl 17 (1954) 1-102.

43. Karvonen MJ. The effect of temporal patterns of work on lifting and handling activities. In: Davis PR, Troup JDG, ed. Proceedings of the Seminar on the Prevention of Low Back Pain, Luxembourg 1983. Taylor \& Francis Ltd, London (in press).

44. Karvonen MJ, Viitasalo JT, Komi PV, Nummi J, Järvinen $T$. Back and leg complaints in relation to muscle strength in young men. Scand $J$ Rehabil Med 12 (1980) 53-60.

45. Kazarian LE. Dynamic response characteristics of the human vertebral column. Acta Orthop Scand Suppl 146 (1972) $1-186$.

46. Kazarian LE. Creep characteristics of the human spinal column. Orthop Clin N Am 6 (1975) 3-18.

47. Kellgren JH, Lawrence JS. Rheumatism in miners: Part II X-ray study. Br J Ind Med 9 (1952) 197-207.

48. Kelsey JL. An epidemiological study of the relationship between occupations and acute herniated lumbar intervertebral dises. Rheumatol Rehabil 14 (1975) $144-159$.

49. Keyserling WM, Herrin GD, Chaffin DB. Isometric strength testing as a means of controlling medical incidents on strenuous jobs. J Occup Med 22 (1980) 332-336.

50. Keyserling WM, Herrin GD, Chaffin DB, Armstrong $\mathrm{TJ}$, Foss ML. Establishing an industrial strength testing program. Am Ind Hyg Assoc J 41 (1980) $730-736$.

51. Krämer J. Intervertebral disk diseases: Causes, diagnosis, treatment and prophylaxis. Georg Thieme Verlag, Stuttgart 1981

52. Krämer J, Gritz A. Körperlangenäderungen durch druckabhängige Flüssigkeitsverschiebung im Zwischenwirbelabschnitt. Z Orthop 118 (1980) 161-164.

53. Lagerlöf E, Kilbom A, Broberg E, Liew M. Work 
related back injuries and other injuries to the musculoskeletal system. National Board of Occupational Safety and Health, Solna, Sweden 1983.

54. Lawrence JS. Rheumatism in miners: Part III Occupational factors. Br J Ind Med 12 (1955) 249-261.

55. Lawrence JS. Disc degeneration: Its frequency and relationship to symptoms. Ann Rheum Dis 28 (1969) $121-138$.

56. Leskinen TPJ, Stålhammar HR, Kuorinka IAA, Troup JDG. The effect of inertial factors on spinal stress when lifting. Eng Med 12 (1983) 87-89.

57. Leskinen TPJ, Stålhammar HR, Kuorinka IAA, Troup JDG. A dynamic analysis of spinal compression with different lifting techniques. Ergonomics 26 (1983) 595-604.

58. Liu YK, Njus G, Buckwalter J, Wakano K. Fatigue response of lumbar intervertebral joints under axial cyclic loading. Spine 8 (1983) 857-865.

59. Lloyd DCEF, Troup JDG. Recurrent back pain and its prediction. J Soc Occup Med 33 (1983) 66-74.

60. Magora A. Investigation of the relation between low back pain and occupation: Part II Work history. Ind Med Surg 39 (1970) 504-510.

61. Magora A. Investigation of the relation between low back pain and occupation: Part III Physical requirements: Sitting, standing and weight lifting. Ind Med Surg 41 (1972) 5-9.

62. Magora A. Investigation of the relation between low back pain and occupation: Part IV Physical requirements: Bending, rotation, reaching and sudden maximal effort. Scand J Rehabil Med 5 (1973) 186-190.

63. Manning DP, Mitchell RG, Blanchfield PL. Body movements and events contributing to accidental and non-accidental back injuries. Spine (in press).

64. Merriam WF, Burwell RG, Mulholland RC, Pearson $\mathrm{JCG}$, Webb JK. A study revealing a tall pelvis in subjects with low back pain. J Bone Jt Surg 65-B (1983) $153-156$.

65. Meyers J, Riordan R, Mattmiller B, Pelcher O, Levenson BS, White AH. Low back injury prevention at Southern Pacific Railroad. Paper read at the 1981 meeting of the International Society for the Study of the Lumbar Spine, New Orleans.

66. Mital A, Okolie ST. Influence of container shape, partitions, frequency, distance and height level on the maximum acceptable amount of liquid carried by males. Am Ind Hyg Assoc J 43 (1982) 813-819.

67. National Institute for Occupational Safety and Health. Work practices guide for manual lifting. US Department of Health and Human Services, Washington, DC 1981. (NIOSH technical report, publication no $81-122$ )

68. Newman PH. The etiology of spondylolisthesis. J Bone Jt Surg 45-B (1963) 39-59.

69. Nicholson AS, Davis PR, Sheppard NJ. Magnitude and distribution of trunk stresses in telecommunications engineers. Br J Ind Med 38 (1981) 364-371.

70. Nordgren B, Schéle R, Linroth K. Evaluation and prediction of back pain during military field service. Scand J Rehabil Med 12 (1980) 1-8.

71. Nordin M. Methods for studying work load with special reference to the lumbar spine. University of Göteborg, Göteborg 1982. (Doctoral dissertation).

72. Pedersen PA. Prognostic indicators in low back pain. J R Coll Gen Pract 31 (1981) 209-216.

73. Perey $O$. Fracture of the vertebral end-plate in the lumbar spine: An experimental biomechanical investigation. Acta Orthop Scand Suppl 25 (1957) 1-101.

74. Raistrick A. Nurses with back pain - Can the problem be prevented? Nurs Times 14th May (1981) 853 - 856 .

75. Redfield JT. The low back $x$-ray as a pre-employment screening tool in the forest products industry. J Occup Med 13 (1971) 219-226.
76. Reilly T, Tyrrell AR, Troup JDG. Circadian variation in stature. $\mathrm{J}$ Chronobiol (in press).

77. Rowe ML. Low back pain in industry: A position paper. J Occup Med 11 (1969) 161-169.

78. Saari J, Wickström G. Load on back in concrete reinforcement work. Scand J Work Environ Health 4 (1978): suppl 1, 13-19.

79. Scott V, Gijsbers K. Pain perception in competitive swimmers. Br Med J 283 (1981) 91-93.

80. Shannon HS, Manning DP. The use of a model to record and store data on industrial accidents resulting in injury. J Occup Accid 3 (1980) 57-65.

81. Snook SH. The design of manual handling tasks in industry. Ergonomics 21 (1978) 963-985.

82. Snook SH, Campanelli RA, Hart JW. A study of three preventive approaches to low back injury. J Occup Med 20 (1978) 478-481.

83. Stubbs DA, Buckle PW, Hudson MP, Rivers PM, Worringham $\mathrm{CJ}$. Back pain in the nursing profession: I Epidemiology and pilot methodology. Ergonomics 26 (1983) 755-765.

84. Stubbs DA, Nicholson AS. Manual handling and back injuries in the construction industry: An investigation. J Occup Accid 2 (1979) 179-190.

85. Svensson H-O. Low back pain in $40-47$ year old men: II Socio-economic factors and previous sickness absence. Scand J Rehabil Med 14 (1982) 55-60.

86. Svensson H-O, Andersson GBJ. Low back pain in 40-47 year old men: Work history and work environment factors. Spine 8 (1983) 272-276.

87. Svensson $\mathrm{H}-\mathrm{O}$, Vedin A, Wilhelmsson C, Andersson GBJ. Low back pain in relation to other diseases and cardiovascular risk factors. Spine 8 (1983) 277-285.

88. Tauber J. An unorthodox look at backache. J Occup Med 12 (1970) 128-130.

89. Tilley $P$. Is sacralization a significant factor in lumbar pain? J Am Osteopath Assoc 70 (1970) 238-241.

90. Troup JDG. Mechanical factors in spondylolisthesis and spondylolysis. Clin Orthop Relat Res 117 (1976) $59-67$

91. Troup JDG. Drivers' back pain and its prevention: A review of the postural, vibratory and muscular factors, together with the problem of transmitted road shock. Appl Ergon 9 (1978) 207-214.

92. Troup JDG. Straight-leg-raising [SLR] and the qualifying tests for increased root tension: Their predictive value after back and sciatic pain. Spine 6 (1981) $526-527$.

93. Troup JDG, Edwards FC. Manual handling and lifting: An information and literature review with special reference to the back. Health \& Safety Executive, Her Majesty's Stationery Office, London (in press).

94. Troup JDG, Leskinen TPJ, Stálhammar HR, Kuorinka IAA. A comparison of intraabdominal pressure increases, hip torque, and lumbar vertebral compression in different lifting techniques. Hum Factors 25 (1983) 517-525

95. Troup JDG, Martin JW, Lloyd DCEF. Back pain in industry: A prospective survey. Spine 6 (1981) $61-69$.

96. Tyrrell AR, Reilly T, Troup JDG. Circadian variation in stature and the effects of spinal loading. Spine (in press).

97. Videman T, Nurminen T, Tola S, Kuorinka I, Vanharanta $H$, Troup JDG. Low-back pain in nurses and some loading factors of work. Spine 9 (1984) $400-$ 404

98. Wickström G. Symptoms and signs of degenerative back disease in concrete reinforcement workers. Scand J Work Environ Health 4 (1978): suppl 1, $1-12$.

99. Wilson RN, Wilson S. Low backache in industry A review of 1,163 cases. Br Med J 2 (1955) 649-652.

100. Wilson RN, Wilson S. A ten-year follow-up of cases 
of low back pain. Practitioner 192 (1964) 657-660.

101. Woodyard JE. Injury, compensation claims and prognosis: Part I. J Soc Occup Med 30 (1980) 2-5.

102. Woodyard JE. Injury, compensation claims and prognosis: Part Il. J Scc Occup Med 30 (1980) $57-60$.
103. Wright B. Lifting and moving patients: 1. An investigation and commentary. Nurs Times 11 th November (1981) 1962-1965.

104. Wright B. Lifting and moving patients: 2 . Training and management. Nurs Times 18th November (1981) $2025-2028$ 